\title{
SYNTHESIS, IN SILICO MOLECULAR DOCKING STUDIES AND ANTIBACTERIAL ACTIVITY OF 4-(4-HYDRAZINYLBENZYL)-1,3-OXAZOLIDIN-2-ONE AGAINST DNA GYRASE ENZYME
}

\author{
P. Jacquline Rosy ${ }^{1}$, S. Kalyanasundaram ${ }^{2}$, K. Santhanalakshmi ${ }^{1}$, \\ S. Muthukumar ${ }^{1}$ \\ ${ }^{1}$ Department of chemistry, I.F.E.T College of Engineering, Gangarampalayam, Villupuram, India \\ ${ }^{2}$ Department of chemistry, Poompuhar College (Autonomous), Melaiyur, \\ India - 609107 \\ E-mail address: skalyanasundharam@gmail.com
}

Keywords: synthesis; antibacterial activity; 4-(4-hydrazinylbenzyl)-1,3-oxazolidin-2-one

\begin{abstract}
The molecular docking and antimicrobial activity studies of synthesized 4-(4hydrazinylbenzyl)-1,3-oxazolidin-2-one were performed, in order to provide insights into the mechanism of action of potential antimicrobial drugs for resistant microorganisms. antimicrobial activity of compounds was investigated in vitro under aseptic conditions, using the disk diffusion method, against various gram positive and gram negative pathogenic microorganisms such as Pseudomonas aeruginosa, Staphylococcus aureus, Escherichia coli, Bacillus substilis and Staphylococcus aureus. Molecular docking was performed to study the binding activity of synthesized hydrazide onto the active site of DNA Gyrase Protein in an effort to increase the understanding of the action and resistance of synthesized hydrazide in this bacterium.
\end{abstract}

\section{INTRODUCTION}

Hydrazines and their derivatives constitute an important class of compounds that has found wide utility in organic synthesis [1,]. While hydrazines have traditionally been employed as reagents for the derivatization and characterization of carbonyl compounds, in recent years the N-N linkage has been used as a key structural motif in various bioactive agents. In particular, an increasing number of N-N bond-containing heterocycles have made their way into commercial applications as pharmaceutical and agricultural agents. The hydrazides are very useful starting materials for the construction of several functionalized heterocyclic with a broad spectrum of biological activities, and consequently they have been studied in considerable detail over the decades 2 . For instance, hydrazides are versatile raw materials to synthesize pyrroles, pyrazoles, 1,3-thiazoles, 1,3,4-oxadiazoles , 1,2,4-triazoles , 1,3,4- thiadiazoles, 1,2,4-triazolo[3,4- $b]$-1,3,4thiadiazoles and 1,2,4-triazolo[3,4-b]-1,3,4-thiadiazines. The common practical route for hydrazide synthesis is the treatment of esters with hydrazine hydrate.

Hydrazides constitute an important class of biologically active organic compounds and their therapeutic uses are well documented in the literature 3 . Hydrazides and their condensation products are reported to possess a wide range of biological activities including antibacterial activity 4, tuberculostatic 5, HIV inhibitors 6, pesticidal 7, antifungal 8, Hydrazides possessing an azometine $\mathrm{NHN}=\mathrm{CH}-$ Proton constitute an important class of compounds for new drug development. Therefore, many researchers have synthesized these compounds as target structures and evaluated their biological activities. Acid hydrazides have frequently been investigated for testing their potentiality as biological properties such as anti-convulsant [9], anti-helmintic [10], anti-tumor 
[11], anti-leprotic [12], anti-malarial [13], anti-cancer [14], anti-depressant [15], anti-HIV [16], analgesic-anti-inflammatory [17], leishmanicidal [18], vasodilator activities [19].

The present investigation deals with the clinically isolated different gram positive and gram negative bacteria against synthesized compounds and most of the tested compounds act as potent antibacterial agents. To understand the interactions of tested compounds at active sites of protein receptors, topoisomerase II DNA gyrase enzymes (PDB ID. PDB: 3U2D) molecular docking studies were also preformed and reported in this article. DNA gyrase is a major bacterial protein that is involved in replication \&transcription and catalyzes the negative supercoiling of bacterial circular DNA. The enzyme consists of two subunits, A and B, of molecular mass 97 and $90 \mathrm{kDa}$, respectively, with the active enzyme being an A2B2 complex. The A subunit of DNA gyrase is involved in DNA breakage and reunion while the B subunit catalyzes the hydrolysis of ATP(20). The DNA gyrase is a known target for antibacterial agents since its blocking induces bacterial death. Hence, the studies are further extended to check probable interactions with this mostly preferred bacterial target(21).

The main objective of this paper is an approach of designing gyrase inhibitor molecules and their derivatives by docking simulations, followed by the synthesis, characterization and antibacterial evaluation was carried out.

\section{MATERIALS AND METHODS.}

All the chemicals and solvents used were of AR grade obtained from Sigma Aldrich, Lobachemie (India). Melting points of the synthesized compounds were determined in open-glass on a Staurt-SMP10 melting point apparatus and recorded in ${ }^{\circ} 0 \mathrm{C}$ without correction. The purity of the compounds was ascertained by thin layer chromatography on silica gel coated aluminum plates (Merck) as adsorbent and UV light as visualizing agent. Synthesized compounds were recrystallised using ethanol as solvent. IR spectra were recorded on SHIMADZU FT-IR spectrometer using $\mathrm{KBr}$ pellet technique. ${ }^{1} \mathrm{H}-\mathrm{NMR}$ spectra were recorded on BRUKER-400 spectrometer operating at 400 $\mathrm{MH}_{\mathrm{Z}}$ using TMS as internal standard in DMSO (chemical shifts in ppm). Protein Structure Preparation The X-ray crystal structures DNA gyrase (PDB: 3U2D) retrieved from the Research Collaboratory for Structural Bioinformatics (RCSB) Protein Data Bank (Figure 1) was used in this study. Water molecules of crystallization were detached from the composite and the protein was optimized for docking using the protein preparation and refinement utility provided by Schrödinger LLC. Partial atomic charges were assigned according to the OPLS-AA force field.

\section{EXPERIMENTAL}

\subsection{Synthesis of 4-(4-hydrazinylbenzyl) 1, 3-oxazolidin-2-one}

(S)-4-(4-aminobenzyl)Oxazolidine-2-one (10gm) was dissolved in $40 \mathrm{ml}$ of demineralised water with Concentrated $\mathrm{HCl}(13 \mathrm{ml})$ were taken in the $\mathrm{RB}$ flask containing sodium nitrite $(3.6 \mathrm{gm})$ solution maintained at $0^{\circ} \mathrm{C}-10^{\circ} \mathrm{C}$ (step 1) were slowly added to Stannous chloride dehydrate $(23.5$ gm) containing Conc. $\mathrm{HCl}(30 \mathrm{ml})$, DM Water $(55 \mathrm{ml})(\operatorname{step} 2)$ Cooled at $0^{\circ} \mathrm{C}$ to $-15^{\circ} \mathrm{C}$. Stirred the reaction mixture for $1 \mathrm{hr}$ and reaction was monitored by TLC. After completion of the reaction, Adjusted the PH of the reaction mass to $4-5$ by using sodium hydroxide solution (30\%).Filtered the reaction mass and suck dried (Solid is Stannous hydroxide). Collect the Mother Liquour. Again adjusted the $\mathrm{PH}$ of the mother liquor to $8-10$ by using Sodium hydroxide solution $(30 \%) 10^{\circ} \mathrm{C}$ to $15^{\circ} \mathrm{C}$. Yellow colour solid ${ }^{22}$ is obtained when maintained reaction for $1 \mathrm{Hr}$ at $10^{\circ} \mathrm{C}$ to $15^{\circ} \mathrm{C}$. 

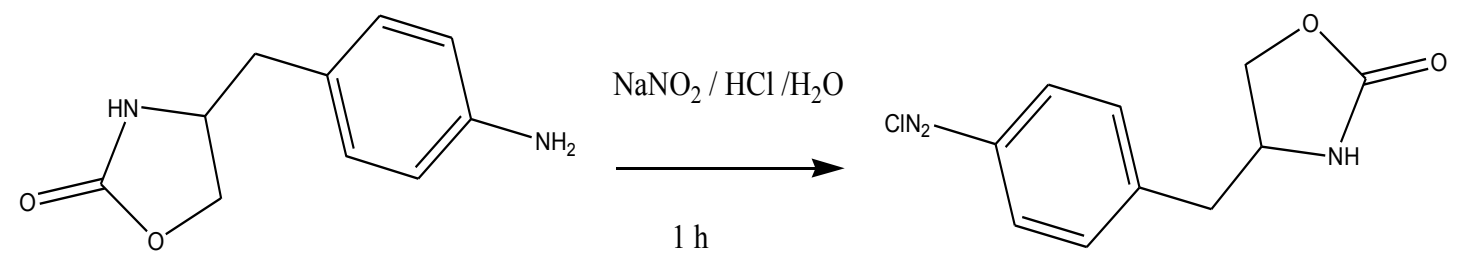

4-(4-aminobenzyl)oxazolidin-2-one

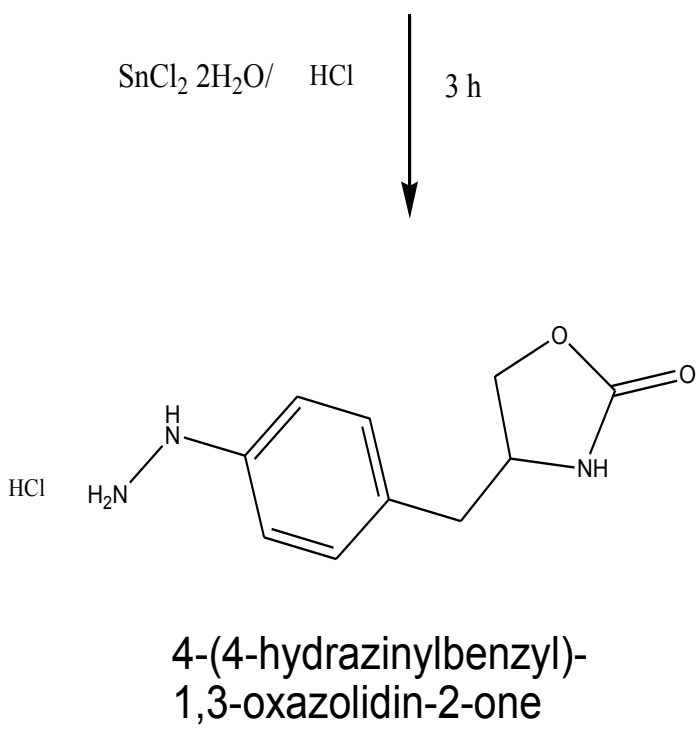

\section{Scheme 1}

\subsection{Analysis of IR spectrum 4-(4-hydrazinylbenzyl) 1, 3-oxazolidin-2-one in $\mathrm{cm}^{-1}$}

A strong band is observed in the region of $1614 \mathrm{~cm}^{-1}$ is due to the Stretching vibration of $-\mathrm{C}-\mathrm{N}$. Band observed at $1680 \mathrm{~cm}^{-1}$ due to $-\mathrm{C}=\mathrm{O}$ group. The band observed at $3041 \mathrm{~cm}^{-1}$ due to the aromatic stretching vibration of $-\mathrm{C}-\mathrm{H}$ bond. The band observed at $2939 \mathrm{~cm}^{-1}$ due to the aliphatic stretching vibration of $-\mathrm{C}-\mathrm{H}$ bond. The aliphatic $-\mathrm{NH}_{2}$ stretching is observed in the range of 3433 $\mathrm{cm}^{-1}$. All the IR values characterizes that the product is 4-(4-hydrazinylbenzyl) 1, 3-oxazolidin-2one. A Singlet is observed at $8.14 \mathrm{ppm}, 7.97 \mathrm{ppm}$ is due to presence of NH proton in Oxazoline ring and $-\mathrm{CH}$ proton in five membered ring. A multiplet is observed in the range of 7.40-7.43 ppm is due to aromatic protons.

\section{MOLECULAR DOCKING STUDIES}

\subsection{Ligand Structure Preparation}

The ligand structures were constructed using the splinter dictionary of Maestro 9.3 (Schrodinger, LLC) using the Optimized Potentials for Liquid Simulations-All Atom (OPLS-AA) force field with the steepest descent followed by curtailed Newton conjugate gradient protocol. Partial tomic charges were computed using the OPLS-AA force field

\subsection{Docking Protocol}

All docking calculations were performed using the "Extra Precision" (XP) mode of GLIDE program. The binding site, for which the various energy grids were designed and stored, was defined in terms of two concentric cubes: the bounding box, which must contain the center of any acceptable ligand pose and enclosing box. It must include all ligand atoms of an acceptable pose, with a Root Mean Square Deviation (RMSD) smaller amount than $0.5 \AA$ and an utmost atomic dislocation of less than $1.3 \AA$ were eliminated as an outmoded in order to increase diversity in the retained ligand poses. The scale factor for van der Waals radii was applied to those atoms with absolute partial charges less than or unchanged to 0.15 (scale factor of 0.8 ) and 0.25 (scale factor of 1.0) electrons for ligand and protein, correspondingly. The max keep variable which sets the maximum number of poses generated during the initial phase docking calculation were set to 5000 
and the keep best variable which sets the number of poses per ligand that enters the energy minimization was set to 1000

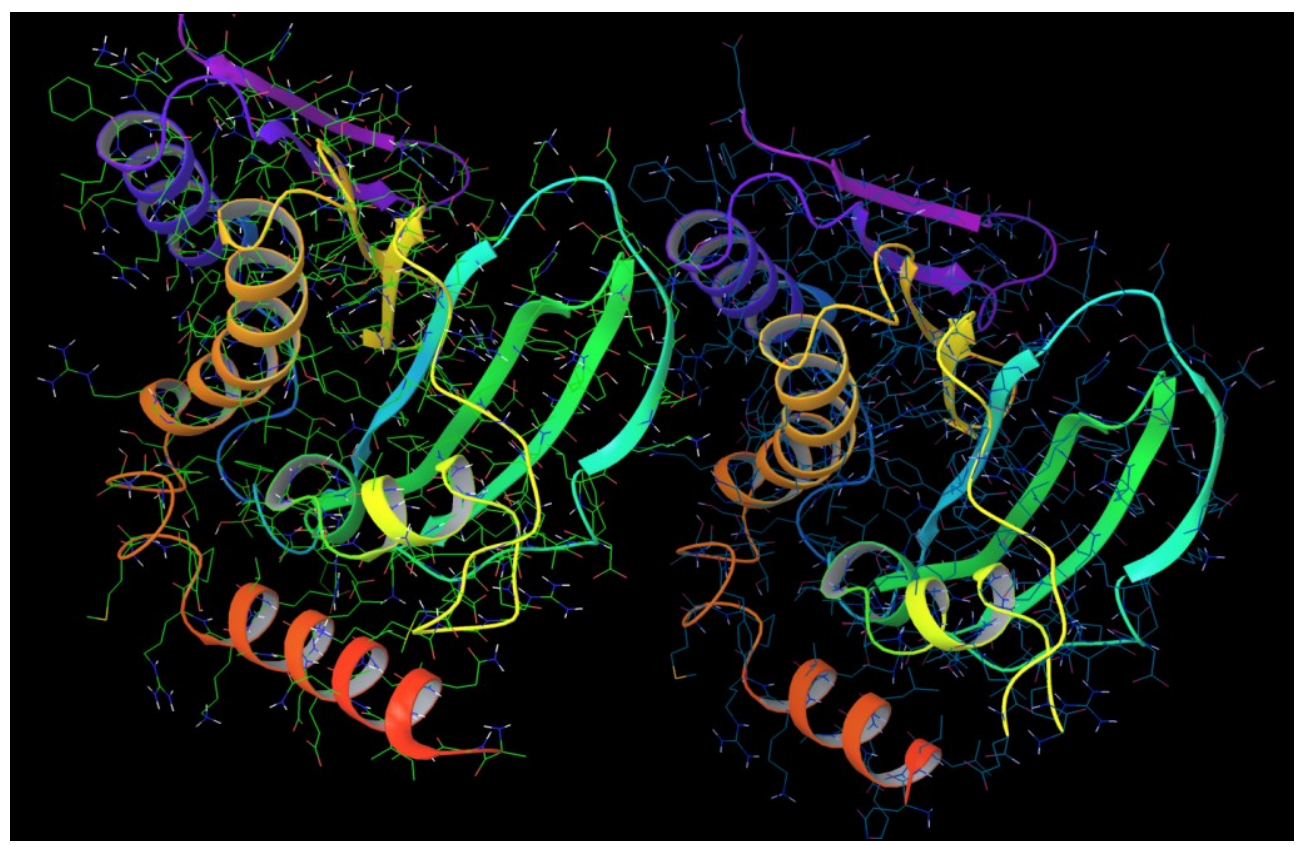

Figure 1: X-ray crystal structure of protein DNA gyrase (PDB: 3U2D)

Energy minimization protocol includes dielectric constant of 4.0 and 1000 conjugate gradient steps. Upon completion of each docking calculation, at most 100 poses per ligand were generated. The paramount docked structure was chosen using a GLIDE score (Gscore) function. One more scoring function used by GLIDE E-model, which itself consequent from a combination of the Gscore, Columbic, van der Waals and the strain energy of the ligand.

Table 1. Molecular docking studies of synthesized 4-(4-hydrazinylbenzyl) 1, 3-oxazolidin-2-one compound

\begin{tabular}{|c|c|c|c|}
\hline S.No & Compound & Glide Score & Glide Energy \\
\hline 1 & $5 \mathrm{a}$ & -5.641159 & -27.394555 \\
\hline 7 & Ciprofloxacin & -7.636035 & -30.0573 \\
\hline
\end{tabular}

Considering the well obtained in vitro results, it was thought worthy to perform molecular docking studies, hence screening the compounds, inculcating both in silico and in vitro results. Considering DNA gyrase as the target receptor, comparative and automated docking studies with newly synthesized compound was performed to determine the best in silico conformation. Fig. 1 shows the native crystal structure of DNA gyrase was obtained from Protein Data Bank (http://www.pdb.org/pdb/home/home.do) with the PDB ID 3U2D.

The synthesized ligand molecules having $2 \mathrm{D}$ structure were converted to energy minimized 3D structures and were further used for in silico protein-ligand docking. 

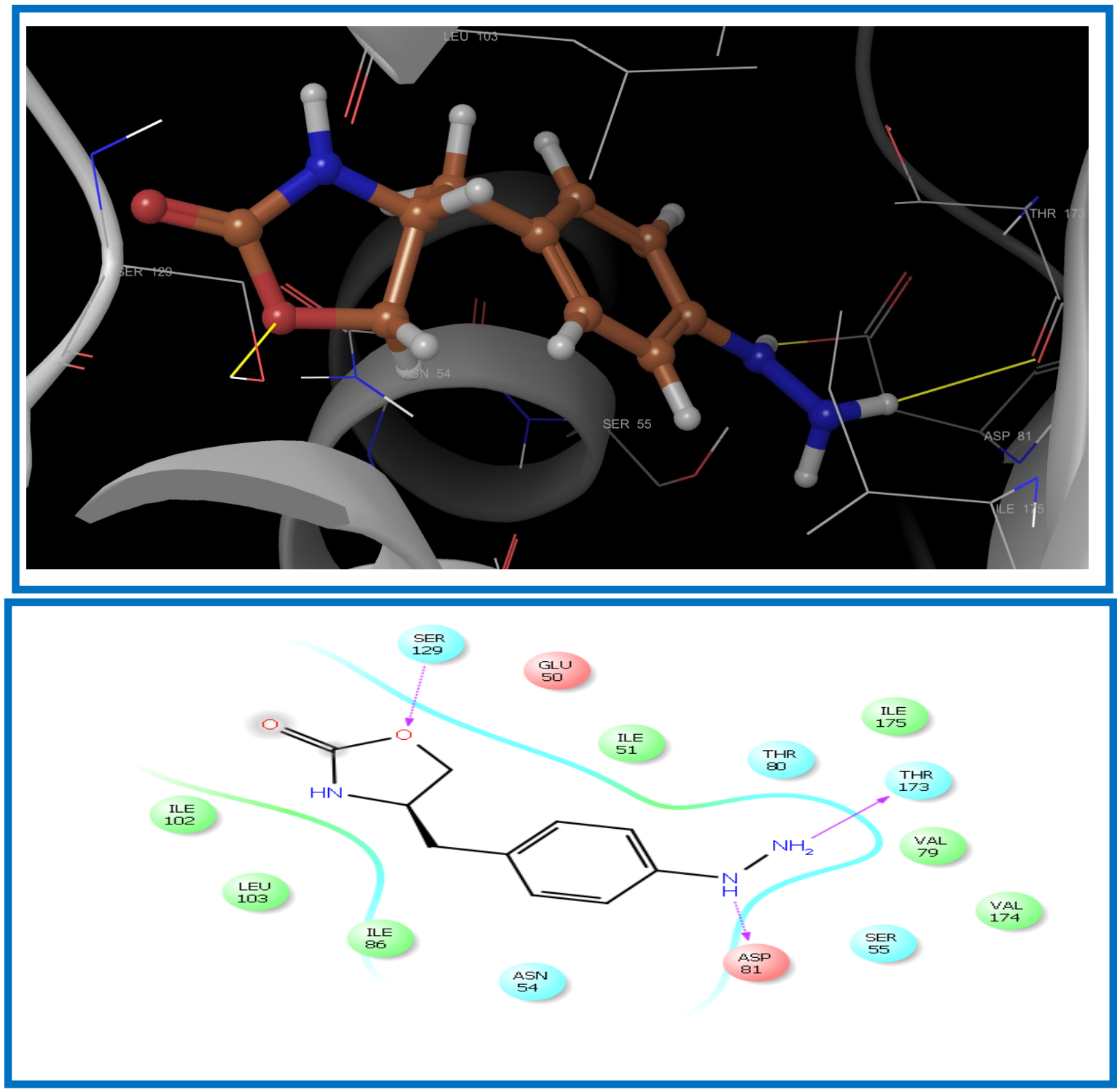

Figure 2: Docking of synthesized 4-(4-hydrazinylbenzyl) 1, 3-oxazolidin-2-one derivative with reference standard ciprofloxacin into the active site of DNA gyrase. The amino acids involved in hydrogen, hydrophobic and van der Waals interactions are highlighted.

Fig. 2 shows the docked images of selected ligands including the considered standard drug i.e. ciprofloxacin. Table 1 shows the Binding Energy and glide score of 4-(4-hydrazinylbenzyl) 1, 3oxazolidin-2-one compound including the standard.

Synthesized Compound revealed docking score -5.641159 with energy score (S) - $27.394555 \mathrm{kcal} / \mathrm{mol}$ and interacted with SER 129, ASP 81 and THR 173 with hydrogen bonds through oxygen atom, $\mathrm{NH}$ and $\mathrm{NH}_{2}$ Present in the compound (Fig. 2). Apart from hydrogen bonding, hydrophobic and van der Waals interactions were also detected with DNA gyrase.

\section{ANTIBACTERIAL ACTIVITY}

All the synthesized compounds were evaluated in vitro for antibacterial activity by using filter paper disc method $(23,24)$ against different strains of bacteria viz. B. substilis, E. coli, S. aureus Pseudomonas aeruginosa and Streptococcus pyogenes. All the compounds along with standard antibacterial Ciprofloxacin were used at 50,150 and $150 \mu \mathrm{g}$ concentrations. Nutrient agar medium was used for the study. After sterilization the nutrient agar medium was melted, cooled and inoculated with three Gram-positive organisms S. aureus, B. subtilis, Streptococcus pyogenes and 
two Gram-negative organisms E. coli, P. aeruginosa and poured into sterile Petri dish to get a uniform thickness of $6 \mathrm{~mm}$. Dried and sterilized filter paper discs $(6 \mathrm{~mm}$ in diameter) soaked with known amount of test agents were placed on the nutrient agar media solidified in petridishes .The standard antibacterial agent Ciprofloxacin $(50 \mu \mathrm{g})$, solvent control and the synthesized compounds in a concentration of 50,100 and $150 \mu \mathrm{g}$ were the plates were then incubated at $37^{\circ} \mathrm{C}$ for $24 \mathrm{~h}$ and the diameter of zone of inhibition were measured and recorded in Table 2.

The zone of inhibition of all compounds is presented in Table 1. Ciprofloxacin was used as standard drug for comparison with test compounds. All analogues, showed comparable antibacterial activity at the dose 50,100 and $150 \mu \mathrm{g} / \mathrm{ml}$ against all the tested strains. Results indicate that compound 4-(4-hydrazinylbenzyl) 1, 3-oxazolidin-2-one showed maximum activity against Bacillus subtilis (zone of inhibition $=21 \mathrm{~mm}$ ), Escherichia coli (zone of inhibition-15), pseudomonas aeruginosa (zone of inhibition $=13 \mathrm{~mm}$ ) Staphylococcus aureus (zone of inhibition-14mm) and against Streptococcus pyogenes (zone of inhibition=20mm) at the dose level of $150 \mu \mathrm{g} / \mathrm{ml}$.

Table -3

Antibacterial activity

\begin{tabular}{|c|l|c|c|c|c|}
\hline \multirow{2}{*}{ S. No. } & \multirow{2}{*}{$\begin{array}{c}\text { Bacteria } \\
\end{array}$} & & $\begin{array}{c}\text { Standard Antibiotic } \\
\text { Disk* }\end{array}$ & \multicolumn{3}{|c|}{$\begin{array}{c}\text { Zone of inhibition mm in diameter } \\
(\mathrm{mm})\end{array}$} \\
\cline { 4 - 6 } & & & 1 & 2 & 3 \\
\hline 1 & Bacillus subtilis & & $\mathbf{5 0 \mu g}$ & $\mathbf{1 0 0} \boldsymbol{\mu g}$ & $\mathbf{1 5 0} \boldsymbol{\mu g}$ \\
\hline 2 & Escherichia coli & 24 & 12 & 16 & 21 \\
\hline 3 & Pseudomonas aeruginosa & 18 & 09 & 13 & 15 \\
\hline 4 & Staphylococcus aureus & 16 & 07 & 11 & 13 \\
\hline 5 & Streptococcus pyogenes & 18 & - & 10 & 14 \\
\hline
\end{tabular}

*Ciprofloxacin

\section{CONCLUSION}

In summary, 4-(4-hydrazinylbenzyl) 1, 3-oxazolidin-2-one derivative was synthesized and characterized by FT-IR and 1HNMR spectral analyses. Synthesized derivative was studied for their interactions with topoisomerase II DNA gyrase enzymes by molecular docking protocol. 4-(4hydrazinylbenzyl) 1, 3-oxazolidin-2-one compound exhibited a good glide score value and glide energy . In vitro antibacterial activity of the tested compounds shows improved activity against all the microorganisms used.

\section{Reference}

[1] Rallas, S.; Gulerman, N.; Erdeniz, H. Synthesis and antimicrobial activity of some new hydrazones of 4-fluorobenzoic acid hydrazide and 3-acetyl-2,5- disubstituted-1,3,4oxadiazolines.Farmaco 2002, 57, 171-174.

[2] Fang, G.-M.; Li, Y.-M.; Shen, F.; Huang, Y.-C.; Li, J.-B.; Lin, Y.; Cui, H.-K.; Liu, L. Protein chemical synthesis by ligation of peptide hydrazides. Angew. Chem. Int. Ed. 2011, 50, 76457649.

[3] R. Bonicke and J.Z. Kracht, Infektionskranch, 139, 140 (1954).

[4] S.K. Agarwal, R. Chandra, R. Gupta and D.R. Tutlani, J. Inst. Chem., 59(5), 225 (1987).

[5] C.N. Haksar, R.C. Malhotra, G. Pandya, and R.K. Sethi, Lab. J. Sc. Technol., 9B, 34 (1971).

[6] F. Binon and R. Royer, J. Chem. Soc., 1358 (1953).

[7] M. Sechi, U. Azzena, M.P. Delussu, R. Dallocchio, A. Dessi, A. Cosseddu, N. Pala and N. Neamati, Molecules, 13, 2442 (2008).

[8] L.U. Kraatz, B.K. Wolfgang, B.G.A. Wolfram, E.T. Andreas and C.M. Norbert, US Patent No. 5929118 (1999). 
[9] A. Maiti, S. Ghosh, (1989) ; Indian Journal of Chemistry, vol . 29, pp- 980-983.

[10] N. Dharmaraj, P. Viswanalhamurthi, K. Natarajan, (2001) ; Trans. Met. Chem. 26, 105.

[11] C.H. Colins, P.M. Lyne, (1970) ; Microhiul Methods, University Park Press, Baltimore .

[12] R.M. Silverstein, G.C. Bassler, T.C. Morrill, Spectrometric Identification of Organic Compounds, fourth ed., Wiley, New York, 1981.

[13] Haack,T.; Fattori,R.; Napoletano,M.; Pellacini,F.; Fronza,G.; Raffaini,G.; Ganazzoli,F.( 2005) ; Bioorg. Med. Chem . vol . 13, pp-4425-4433.

[14] Strappaghetti,G.;Brodi,C.;Giannaccini,G;Betti,L., (2006) ; Bioorg.Med.Chem.Lett. vol .16, pp- 2575-2579.

[15] Al-Assar,F.;Zelenin,K.N.;Lesiovskaya,E.E.;Bezant, I.P.; Chakchir ， B.A. (2002) ; Pharm.Chem. vol .36, pp- 598-603.

[16] H.L. Singh, A.K. Vershney, (2006) ; Bioinorganic chemistry and application . pp.1-7,

[17] Jain ,R.P.;Vederas,J.C. (2004) ; Bioorg. Med.Chem.Lett.vol . 14, pp- 3655-3658.

[18] A. Scozzafava, L. Menabuoni , F. Mincione, G.Mincione, and C. T. Supuran , (2001) Bioorganic and medicinal chemistry Letters vol.11, no.4, pp -575-582,

[19] M. A. Elsome, J .M. T. Hamilton-Miller, W. Brmfitt and W. C. Noble., (1996) ; Journal of Antimicrobial Chemotherapy, vol.37, no5, pp. 911-918.

[20] Amit Poshiya et al, Synthesis studies of bacterial dna-gyrase inhibitors, IJPT, 2011 3(3)| 3048-3059

[21] Smita pawar et al., Synthesis of novel antimicrobial derivatives of 3-substituted pyrrolidine2, 5-diones using pharmacophore hybrid approach: part-I, Int J Pharm Pharm Sci,2014, 6(2), 486-490

[22] Aviraboina Siva Prasad et al Der Pharma Chemica, 2012, 4 (1):347-351

[23] E.W. Koneman, S.D. Allen, W.M. Janda, P.C. Schreckenberger, Colour Atlas and Text Book of Diagnostic Microbiology, 5th ed., Jt. Editor W.C. Winn, Lippincott, Philadelphia, P.A., 1997,185 .

[24] V. Cleidson, M. Simone, F.A.S. Elza Artur S. Jr., Braz. J.microbiol., 2007, 38(2), 369-380. 